\title{
Semen Analysis of Total Motile Sperm Count Based on the 1999 and 2010 WHO Criteria
}

\author{
Patrícia de Moraes De Zorzi ${ }^{1}$, Ana Paula de Souza Kussler ${ }^{1,2}$, Anita Mylius Pimentel ${ }^{2}$, Edison Capp ${ }^{1,3}$, Helena von \\ Eye Corleta ${ }^{1,2,3}$ \\ ${ }^{1}$ Programa de Pós-Graduação em Ciências da Saúde: Ginecologia e Obstetrícia, Medicine School, Universidade \\ Federal do Rio Grande do Sul, Porto Alegre, RS, Brazil \\ ${ }^{2}$ Generar - Human Reproduction, Porto Alegre, RS, Brazil \\ ${ }^{3}$ Department of Obstetrics and Gynecology, Medicine School, Universidade Federal do Rio Grande do Sul, Porto \\ Alegre, RS, Brazil
}

\begin{abstract}
Objective: Approximately $15 \%$ of the couples suffer from infertility. Half of the cases of infertility are due to male factors. Several sperm function tests have been proposed to evaluate male fertility, but sperm analysis is still the first and most important diagnostic test for male infertility. The prognostic value of semen characteristics such as concentration, morphology and motility markers are often confused with male infertility. Evaluation of seminal parameters and classification for normality remains a frequent topic of discussion.

Methods: This study evaluated 477 semen samples from men undergoing investigation or infertility treatment between 2011 and 2015 .

Results: The spermograms of 401 patients were deemed abnormal based on the 1999 World Health Organization (WHO) criteria; the number changed to 223 when the spermograms were assessed based on the 2010 WHO criteria and to 200 when Total Motile Sperm Count (TMSC) was used as the criterion. Sperm morphology was the item in the criteria that most significantly changed spermogram classification. Normality parameters became less rigid from 1999 to 2010, thereby significantly changing the proportion of individuals no longer described as infertile/subfertile.

Conclusions: The classification based on TMSC could not differentiate between fertile and infertile subjects for not taking sperm morphology into account. Nevertheless, it may be helpful in cases where intrauterine insemination is indicated.
\end{abstract}

Keywords: male fertility, semen analysis, seminal parameters, sperm function

\section{INTRODUCTION}

Approximately $15 \%$ of the couples suffer from infertility. Half of the cases of infertility are due to male factors (Tharakan et al., 2021). Several sperm function tests have been proposed to evaluate male fertility, but spermograms are the main diagnostic tool for male infertility (Talwar \& Hayatnagarkar, 2015; Zhang et al., 2014).

Semen analysis is extremely important in the investigation of infertile couples and in the determination of a couple's ability to become pregnant. Before the publication of the World Health Organization (WHO) Manual in 1999, laboratories used different methods to obtain and analyze data and adopted diverse definitions for male fertility. This produced error in the identification of normal range values and led to the categorization of fertile men as infertile, when the ranges used to describe normality were too high and unrealistic, or infertile men as fertile, when the ranges were lower than what was needed to produce pregnancy.
On the other hand, the population of men studied for the 2010 WHO Manual comprised individuals without proven paternity, patients attending human reproduction clinics seeking treatment, semen donors, and vasectomy candidates. In the last two groups of men, the first may be fertile because they have normal values and the second group is very likely to be fertile, although there is no data on the time it took for their partners to become pregnant (Vieira, 2013). Routine semen analysis alone has its limitations, since it does not take sperm dysfunctions such as immature chromatin or sperm DNA damage into consideration (Esteves et al., 2012).

Semen parameter evaluation, patient classification, and the definition of what constitutes normal range values are topics for discussion. In 1980, the first of five issues of the WHO Laboratory Manual for the Examination of Human Semen was published. The negative point of this first classification is that it was not validated by prospective studies (Catanzariti, 2013).

In 1999, the WHO described normal semen parameters based only on the study of fertile couples. This classification was based on data coming from various laboratories using different methodologies, and analyzed a number of populations without a standardized definition for fertile populations (Cooper et al., 2010).

In 2010, the WHO published more stringent guidelines, based on men who had naturally conceived children, a fact that does not necessarily imply that men with lower semen parameters are infertile (Hamilton et al., 2015). The new cutoff points were defined based on a study that included 1,953 men from various countries, whose wives became pregnant within less than a year. Values below the $5^{\text {th }}$ percentile of this group were considered abnormal. Normality was assigned to individuals with a Kruger score of $4 \%$ or higher. In addition, sperm motility classification was no longer used to separate sperm into grades $a, b, c$ or $d$; instead, sperm was rated as having progressive motility, non-progressive motility, or immotile (WHO). Another classification studied is based on the Total Motile Sperm Count (TMSC). The result is obtained by multiplying the ejaculate volume by sperm concentration in milliliters and the proportion of motile sperm $(a+b)$ divided by $100 \%$, without taking into account the morphology or the performed seminal preprocessing (Ayala et al., 1996).

Therefore, the objective of this study was to evaluate and compare the influence of different semen classifications (1999 and 2010 WHO criteria; TMSC) on the diagnosis of male infertility.

\section{MATERIAL AND METHODS}

This longitudinal retrospective study reviewed patient charts and looked into the characteristics of 477 male patients treated or tested for infertility between 2011 and 
2015 at a private assisted reproduction clinic in Porto Alegre (Generar Human Reproduction). All patients in the period were enrolled $(n=477)$. The Ethics Committee of the Hospital das Clínicas of Porto Alegre approved this study and awarded it certificate no. 20 16-0524. The collected data included age, use of medications, comorbidities, body mass index (BMI), days of abstinence, volume, concentration, motility, morphology (according to Tygerberg), round cells, leukocytes, vitality, and TMSC calculation. A single embryologist performed all semen evaluations.

Statistical analyses were performed on software package SPSS version 21.0, with the significance level set at $5 \%(p \leq 0.05)$. Quantitative variables expressed as means and standard error or as medians and interquartile ranges. Categorical variables were described with absolute and relative frequencies. Student's t-test was used to compare between means. Proportions were compared with Pearson's chi-squared test or Fisher's exact test. McNemar's test was used to compare between the alterations resulting from the use of the 1999 and 2010 WHO criteria.

\section{RESULTS}

Semen samples of 477 patients aged 37 years on average were analyzed. Approximately $21 \%$ were obese and $10 \%$ smoked. More than $25 \%$ reported having comorbidities; $1 \%$ reported prior cancer treatment; $4.5 \%$ said they had taken psychoactive drugs; $5 \%$ had hypertension; $1.3 \%$ had insulin resistance; and $2.5 \%$ reported dyslipidemia.

The data on semen samples is shown in Table 1 . The mean period of sexual abstinence before collection of semen was $3.65 \pm 1.77$ days.

Significant changes were observed in almost every parameter when the 1999 and 2010 WHO criteria were compared, with the exception of total concentration. Of the 477 samples analyzed, $293(61.4 \%)$ had at least two alterations according to the 1999 criteria; the number dropped to $112(23.5 \%)$ when the samples were analyzed vis-à-vis the 2010 criteria.

Considering absolute and relative differences, the three parameters for which most alterations were found based on the 2010 criteria were morphology, vitality, and motility $a+b$ (Table 2). Figure 1 illustrates these differences, with morphology showing as the parameter with most alterations according to the 1999 criteria that were rated as normal based on the 2010 criteria. Table 2 confirms this finding, as $85.1 \%$ of the samples did not show any alteration in morphology when they were classified based on the 2010 WHO criteria. When semen samples were

\begin{tabular}{|l|c|}
\hline \multicolumn{2}{|l|}{ Table 1. Data from semen samples. } \\
\hline Variables & Data \\
\hline Days of abstinence* & $3.65 \pm 1.77$ \\
\hline Volume $(\mathrm{mL}) *$ & $2.84 \pm 1.43$ \\
\hline Concentration $(\times 106) \#$ & $32(8-62)$ \\
\hline Motility a+b $(\%)^{*}$ & $38.6 \pm 17.5$ \\
\hline Round cells $(\times 106) \#$ & $2.6(1.2-4.9)$ \\
\hline Leukocytes $(\times 106) \#$ & $0.8(0.4-1.2)$ \\
\hline Vitality $(\%)^{*}$ & $58.4 \pm 15.8$ \\
\hline Normal morphology $(\%) \#$ & $10(6-15)$ \\
\hline TMSC $(\times 106) \#$ & $28.9(5.1-73.7)$ \\
\hline
\end{tabular}

*mean \pm standard deviation; \# median (percentile 2575). TMSC: Total Motile Sperm Count analyzed based on the three classifications studied, 401 $(84.1 \%)$ had alterations by the 1999 WHO criteria, 223 $(46.8 \%)$ by the 2010 WHO criteria, and 200 (41.9\%) had alterations based on TMSC (Table 3 ).

When at least two of the clinically relevant semen parameters (total concentration, concentration per $\mathrm{ml}$, motility and morphology) were altered, the number of samples considered abnormal decreased to $61.4 \%$ based on the 1999 WHO criteria and to $23.5 \%$ based on the 2010 WHO criteria (Table 3).

The analysis of the associations between normal $(\geq 20$ million) and altered samples ( $<20$ million) based on TMSC and the 1999 and 2010 WHO classifications are presented in Table 4. There was a significant association in all parameters. Of the 200 samples considered altered based on TMSC, 192 (96\%) had at least two alterations based on the 1999 WHO criteria, compared with 108 (54\%) according to the $2010 \mathrm{WHO}$ classification. On the other hand, of the 277 samples considered normal by TMSC, 101 (36.5\%) had more than two alterations based on the 1999 WHO criteria and only four $(1.4 \%)$ had more than two alterations according to the 2010 WHO criteria.

Patients with motility alterations based on the 1999 and 2010 WHO criteria were significantly older and presented no association with TMSC. Based on the 1999 WHO criteria, men with motility disorders had significantly more days of abstinence (Table 5) without associations with TMSC or the 2010 WHO criteria.

Smokers and patients with comorbidities showed a higher proportion of morphology alterations based on the 2010 WHO criteria. There was no association when these samples were categorized based on the 1999 WHO criteria or TMSC (Table 5).

In patients with volume alterations, the 1999 WHO criteria found a higher proportion of individuals with hypertension (9.5\% vs. 3.6\%, $p=0.023)$ and shorter abstinence periods (Table 5). The 2010 WHO criteria and TMSC were not significantly associated with these variables.

Higher proportions of decreased sperm vitality were found in smokers and older individuals based on the 2010 WHO criteria (Table 5). The same semen samples categorized based on the 1999 WHO criteria and TMSC had no significant association.

Based on the 1999 WHO criteria, $25.4 \%$ of the obese patients had at least one alteration versus $15.8 \%$ of the patients with a BMI $<30(p=0.02)$; patients with two or more alterations based on the 1999 WHO classification had significantly higher BMIs (Table 5 ). These associations were not found in the 2010 WHO criteria or TMSC.

\section{DISCUSSION}

The 1999 WHO criteria for normality in semen analysis was quite stringent, and led to the categorization of men as infertile solely for their inability to conceive naturally, an element later revised in the 2010 criteria. Catanzariti et al. (2013) evaluated 529 semen samples from fertile and infertile patients and found that $199(37.83 \%)$ patients were deemed normal by both criteria, $246(46.77 \%)$ were abnormal based on the two criteria, and 82 (15.59\%) were abnormal based on the 1999 criteria and normal on the 2010 WHO classification. Fifteen percent of the patients deemed abnormal based on the 1999 WHO criteria were categorized as having normal semen parameters in the 2010 classification (Catanzariti et al., 2013).

The samples included in this study were taken from patients seen at an assisted reproduction clinic. Approximately $84 \%$ of the samples had alterations in every parameter based on the 1999 WHO criteria; the proportion dropped to $46.8 \%$ in the 2010 criteria. When at least two clinically relevant parameters were analyzed, $61.4 \%$ had 


\begin{tabular}{|c|c|c|c|c|c|}
\hline \multirow[b]{2}{*}{ Alterations } & \multicolumn{2}{|c|}{ WHO } & \multirow{2}{*}{$\begin{array}{c}\text { Absolute } \\
\text { Difference } \\
(\%)\end{array}$} & \multirow{2}{*}{$\begin{array}{c}\text { Relative } \\
\text { Difference } \\
(\%)\end{array}$} & \multirow[b]{2}{*}{$\boldsymbol{p}$} \\
\hline & $\begin{array}{c}1999 \\
n=477 \\
(\%)\end{array}$ & $\begin{array}{c}2010 \\
n=477 \\
(\%)\end{array}$ & & & \\
\hline Total concentration & $163(34.2)$ & $162(34.0)$ & 0.2 & 0.6 & 1.000 \\
\hline Concentration/ml & $170(35.6)$ & $146(30.6)$ & 5.0 & 14.0 & $<0.001$ \\
\hline Motility $a+b$ & $310(65.0)$ & $151(31.7)$ & 33.3 & 51.2 & $<0.001$ \\
\hline Morphology & $335(70.2)$ & $50(10.5)$ & 59.7 & 85.0 & $<0.001$ \\
\hline Vitality & $400(87.9)$ & $175(38.5)$ & 49.4 & 56.2 & $<0.001$ \\
\hline With at least 1 abnormal parameter* & $401(84.1)$ & $223(46.8)$ & 37.3 & 44.4 & $<0.001$ \\
\hline With at least 2 abnormal parameters* & $293(61.4)$ & $112(23.5)$ & 37.9 & 61.7 & $<0.001$ \\
\hline
\end{tabular}

*The patient had alterations in any of the four parameters: total concentration, concentration/ml, motility and morphology. WHO: World Health Organization.

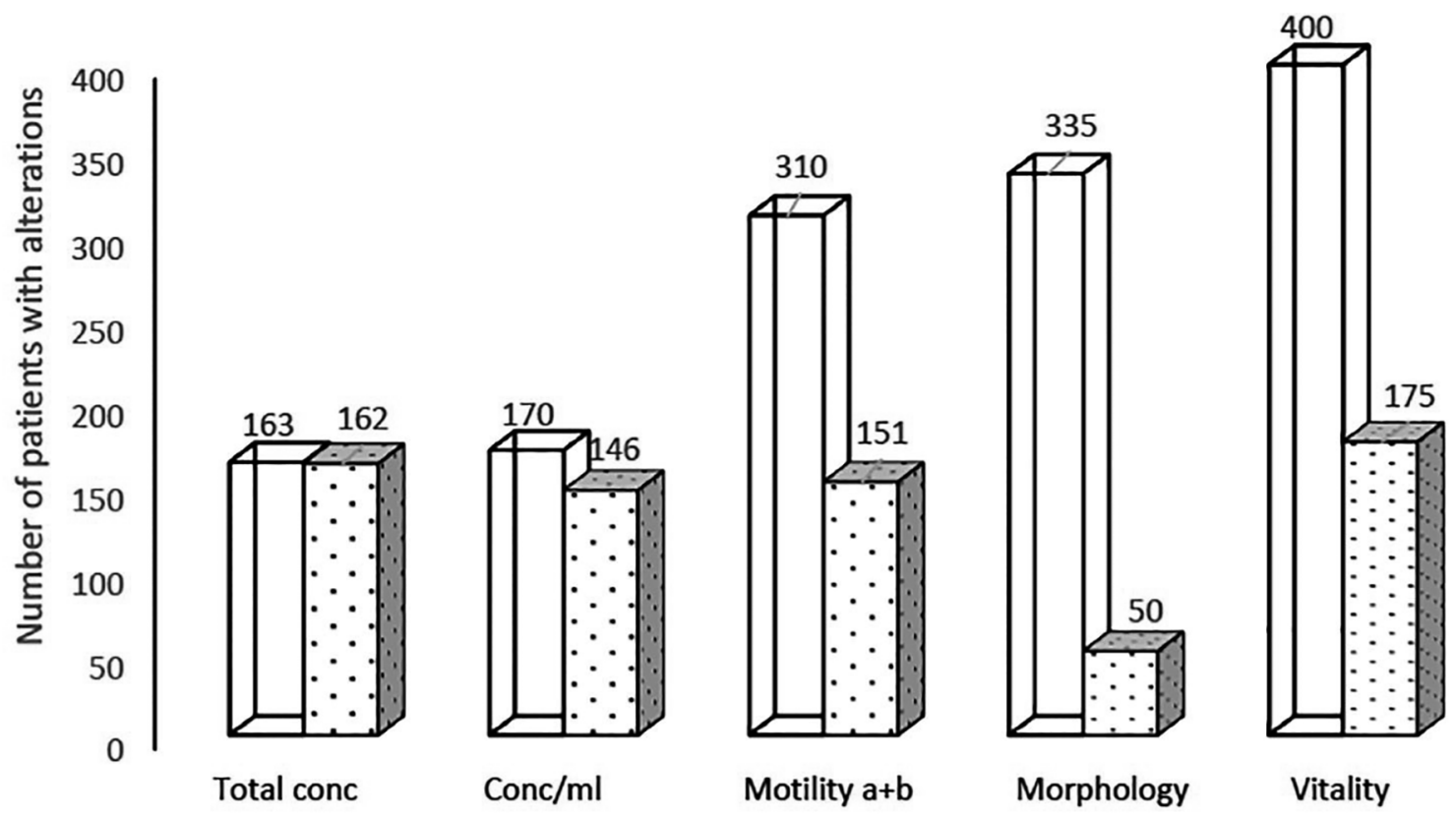

WHO parameters $\mathbf{\square} 1999$ 田2010

Figure 1. Number of patients with alterations in sperm parameters according to the 1999 and 2010 WHO criteria WHO: World Health Organization.

altered results in the 1999 WHO criteria against $23.5 \%$ in the 2010 classification, thereby confirming that the 1999 criteria overestimated the number of abnormal samples and cases of infertility.

Semen parameters in the 2010 WHO classification became less stringent, thus increasing the number of men with normal tests. The parameter that most influenced the difference between the classifications was morphology: $85.1 \%$ of altered samples based on the 1999 WHO criteria were deemed normal based on the 2010 criteria, along with vitality (56.3\%) and motility $a+b(51.3 \%)$. Only $0.6 \%$ had alterations in total concentration. Although morphology was the parameter with the greatest difference between classifications, it is not the most important element associated with reproductive outcomes. A study that evaluated 856 intrauterine insemination (IUI) cycles found no significant difference in the pregnancy rates of patients with a morphology score smaller or larger than $4 \%(17.3 \%$ versus $16.7 \%$ ), suggesting that alterations in morphology should not be used in isolation as an indicator to refer patients to in vitro fertilization (IVF) (Deveneau et al., 2014).

Erdem et al. (2016) found no impact from morphology in the live birth rates of couples with unexplained infertility treated with IUI, although higher live birth rates were seen in couples with male subfertility when more than $4.5 \%$ of the spermatozoa had normal morphology.

A recent meta-analysis (Wang et al., 2019) suggested that varicocelectomy results in a significantly improved not only in TMSC but also in spontaneous pregnancy rate. This improvement is greater in patients with mildly or moderately decreased TMSC. Hamilton et al. (2015) evaluated 1177 patients with male infertility and unexplained 


\begin{tabular}{|c|c|c|}
\hline Variables & $N=477$ & $\%$ \\
\hline $\begin{array}{l}1999 \text { WHO classification } \\
\text { Total concentration }<40 \text { million } \\
\text { Concentration } / \mathrm{ml}<20 \times 106 \\
\text { Motility } \mathrm{a}+\mathrm{b}<50 \% \\
\text { Morphology }<14 \% \\
\text { With alterations }-4 \text { general criteria* } \\
\text { With at least } 2 \text { alterations } \\
\end{array}$ & $\begin{array}{l}163 \\
170 \\
310 \\
335 \\
401 \\
293\end{array}$ & $\begin{array}{l}34.2 \\
35.6 \\
65.0 \\
70.2 \\
84.1 \\
61.4\end{array}$ \\
\hline $\begin{array}{l}2010 \text { WHO classification } \\
\text { Total concentration }<39 \text { million } \\
\text { Concentration } / \mathrm{ml}<15 \times 10^{6} \\
\text { Motility } \mathrm{a}+\mathrm{b}<32 \% \\
\text { Morphology }<4 \% \\
\text { With at least } 1 \text { abnormal parameter* } \\
\text { With at least } 2 \text { abnormal parameters* }\end{array}$ & $\begin{array}{c}162 \\
146 \\
151 \\
50 \\
223 \\
112 \\
\end{array}$ & $\begin{array}{l}34.0 \\
30.6 \\
31.7 \\
10.5 \\
46.8 \\
23.5 \\
\end{array}$ \\
\hline $\begin{array}{l}\text { TMSC }\left(\times 10^{6}\right) \\
\quad<20 \\
\quad \geq 20\end{array}$ & $\begin{array}{l}200 \\
277 \\
\end{array}$ & $\begin{array}{l}41.9 \\
58.1\end{array}$ \\
\hline
\end{tabular}

* The patient had alteration in any of the four parameters (total concentration, concentration ml, motility and morphology). TMSC: Total Motile Sperm Count; WHO: World Health Organization

Table 4. Association between TMSC and alterations in the 1999 and 2010 WHO classifications.

\begin{tabular}{|c|c|c|c|}
\hline \multirow{2}{*}{ Variables } & \multicolumn{2}{|c|}{ TMSC (x106) } & \multirow{2}{*}{$\boldsymbol{P}$} \\
\hline & $<20(n=200)$ & $\geq 20(n=277)$ & \\
\hline $\begin{array}{l}1999 \text { WHO Classification } \\
\text { Total concentration }<40 \text { million } \\
\text { Concentration } / \mathrm{ml}<20 \times 10^{6} \\
\text { Motility } a+b<50 \% \\
\text { Morphology }<14 \% \\
\text { With alterations }-4 \text { general criteria* } \\
\text { With at least } 2 \text { alterations }\end{array}$ & $\begin{array}{l}161(80.5) \\
154(77.0) \\
178(89.0) \\
177(88.5) \\
200(100) \\
192(96.0)\end{array}$ & $\begin{array}{c}2(0.7) \\
16(5.8) \\
132(47.7) \\
158(57.0) \\
201(72.6) \\
101(36.5)\end{array}$ & $\begin{array}{l}<0.001 \\
<0.001 \\
<0.001 \\
<0.001 \\
<0.001 \\
<0.001\end{array}$ \\
\hline $\begin{array}{l}2010 \text { WHO Classification } \\
\text { Total concentration }<39 \text { million } \\
\text { Concentration/ } \mathrm{ml}<15 \times 10^{6} \\
\text { Motility } a+b<32 \% \\
\text { Morphology }<4 \% \\
\text { With at least } 1 \text { abnormal parameter* } \\
\text { With at least } 2 \text { abnormal parameters* }\end{array}$ & $\begin{array}{c}160(80.0) \\
140(70.0) \\
129(64.5) \\
46(23.0) \\
193(96.5) \\
108(54.0)\end{array}$ & $\begin{array}{c}2(0.7) \\
6(2.2) \\
22(7.9) \\
4(1.4) \\
30(10.8) \\
4(1.4)\end{array}$ & $\begin{array}{l}<0.001 \\
<0.001 \\
<0.001 \\
<0.001 \\
<0.001 \\
<0.001\end{array}$ \\
\hline
\end{tabular}

*The patient had alterations in any of the four parameters: total concentration, concentration/ ml, motility and morphology TMSC: Total Motile Sperm Count; WHO: World Health Organization.

infertility and categorized the semen samples based on the guidelines of the 2010 WHO criteria and TMSC. TMSC greater than $20 \times 10^{6}$ was deemed normal. When the WHO criteria were used, $76 \%$ of the patients were rated as infertile, while in the evaluation based on TMSC $60 \%$ were deemed infertile.

The patients in our population were compared based on three criteria (1999 WHO, $2010 \mathrm{WHO}$, and TMSC); $84.1 \%$ had an alteration based on the 1999 WHO criteria; $46.8 \%$ based on the 2010 WHO classification; and $41.9 \%$ based on TMSC. Analysis of potential associations between alterations found that none of the parameters (concentration, motility, morphology, volume, and vitality) was significantly associated when TMSC alterations were compared to alterations identified based on the 1999 and 2010 WHO criteria.

Of the 200 samples with alterations based on TMCS, $96 \%$ had at least two alterations based on the 1999 WHO criteria against $54 \%$ in the 2010 criteria. On the other hand, of the 277 samples considered normal based on TMSC, $36.5 \%$ had more than two alterations based on the
1999 WHO criteria and only $1.4 \%$ had more than two alterations based on the 2010 WHO criteria. Since morphology is not considered in TMSC, further studies are needed to compare semen ratings and correlate the findings with natural conception and pregnancy rates in IUI.

This study showed that environmental factors, lifestyle, and chronic diseases worsen semen quality (vitality, morphology, volume), and that aging deteriorates motility and vitality. Other authors have published similar results (Du Plessis et al., 2010; Jurewicz et al., 2014; Kaya et al., 2020; Lingappa et al., 2015). The results published by Borges deserve attention. Over a period of ten years, the semen quality of patients undergoing infertility treatments showed significant decreases in concentration and percentage of normal forms, thus supporting the finding that lifestyle and environmental factors might alter male fertility.

Our study showed that in the period ranging from 1999 to 2010 the parameters became more rigid, which thus decreased the number of individuals categorized as infertile or subfertile. Normal TMSC samples correlate better with 


\begin{tabular}{|c|c|c|c|c|c|c|}
\hline \multirow{2}{*}{ Variables } & \multicolumn{2}{|c|}{ Motility a + b - 1999} & \multirow{2}{*}{$\boldsymbol{p}$} & \multicolumn{2}{|c|}{ Motility $a+b-2010$} & \multirow{2}{*}{$\boldsymbol{P}$} \\
\hline & $<50 \%$ & $\geq 50 \%$ & & $<32 \%$ & $\geq 32 \%$ & \\
\hline Age (years) ${ }^{\#}$ & $37.6 \pm 6.8$ & $35.8 \pm 6.1$ & 0.005 & $38.0 \pm 6.6$ & $36.5 \pm 6.6$ & $0.019 \S$ \\
\hline \multirow[t]{3}{*}{ Days of abstinence \# } & $3.76 \pm 2.02$ & $3.45 \pm 1.15$ & 0.035 & $3.70 \pm 2.32$ & $3.63 \pm 1.45$ & $0.691^{\S}$ \\
\hline & \multicolumn{2}{|c|}{ Morphology (\%) - 1999} & \multirow{2}{*}{$p$} & \multicolumn{2}{|c|}{ Morphology (\%) - 2010} & \multirow{2}{*}{$p$} \\
\hline & $<14$ & $\geq 14$ & & $<4$ & $\geq 4$ & \\
\hline Smoking - n (\%) & $45(10.1)$ & $0(0.0)$ & 1.000 & $9(20.5)$ & $36(8.9)$ & $0.029^{+}$ \\
\hline \multirow[t]{3}{*}{ Presence of comorbidity - $\mathrm{n}(\%)$} & $82(26.0)$ & $33(25.4)$ & 0.982 & $21(44.7)$ & $94(23.6)$ & $0.003^{+}$ \\
\hline & Volume & -1999 & \multirow{2}{*}{$p$} & \multicolumn{2}{|c|}{ Volume $(\mathrm{ml})-2010$} & \multirow{2}{*}{$p$} \\
\hline & $<2$ & $\geq 2$ & & $<1.5$ & $\geq 1.5$ & \\
\hline Hypertension - n (\%) & $11(9.5)$ & $13(3.6)$ & 0.023 & $5(8.3)$ & $19(4.6)$ & $0.208^{+}$ \\
\hline \multirow[t]{3}{*}{ Days of abstinence ${ }^{\#}$} & $3.37 \pm 1.49$ & $3.74 \pm 1.84$ & 0.049 & $3.60 \pm 1.78$ & $3.66 \pm 1.77$ & $0.825^{\S}$ \\
\hline & Vitality & -1999 & \multirow{2}{*}{$p$} & \multicolumn{2}{|c|}{ Vitality (\%) - 2010} & \multirow{2}{*}{$p$} \\
\hline & $<75$ & $\geq 75$ & & $<58$ & $\geq 58$ & \\
\hline Smoking - n (\%) & $42(11.2)$ & $1(1.9)$ & 0.067 & $23(14.2)$ & $20(7.5)$ & $0.039^{+}$ \\
\hline \multirow[t]{3}{*}{ Age (years) ${ }^{\#}$} & $37.0 \pm 6.5$ & $35.7 \pm 5.9$ & 0.177 & $38.5 \pm 7.2$ & $35.8 \pm 5.7$ & $<0.001^{\S}$ \\
\hline & criteria & HO 1999 & \multirow[b]{2}{*}{$p$} & \multicolumn{2}{|c|}{ criteria WHO 2010} & \multirow[b]{2}{*}{$p$} \\
\hline & $\begin{array}{l}\text { With } \\
\text { alteration }\end{array}$ & $\begin{array}{l}\text { Without } \\
\text { alteration }\end{array}$ & & $\begin{array}{c}\text { With } \\
\text { alteration }\end{array}$ & $\begin{array}{l}\text { Without } \\
\text { alteration }\end{array}$ & \\
\hline \multirow[t]{3}{*}{ Obesity - n (\%) } & $62(25.4)$ & $31(15.8)$ & 0.020 & $52(24.2)$ & $41(18.2)$ & $0.157^{+}$ \\
\hline & 2 or more a & rations 1999 & \multirow{2}{*}{$p$} & 2 or more al & ations 2010 & \multirow{2}{*}{$P$} \\
\hline & Yes & No & & Yes & No & \\
\hline BMI $\left(\mathrm{kg} / \mathrm{m}^{2}\right)^{\#}$ & $27.4 \pm 3.8$ & $26.6 \pm 3.8$ & 0.025 & $27.7 \pm 3.6$ & $27.0 \pm 3.9$ & $0.087 \S$ \\
\hline
\end{tabular}

* The same variables were analyzed based on TMSC without statistically significant associations $(p>0.05)$.

\# Mean \pm standard deviation.

$\S$ Student's t-test

+ Pearson's chi-squared test or Fisher's exact tests

TMSC: Total Motile Sperm Count; WHO: World Health Organization

2010 WHO criteria. The importance of sperm morphology in semen analysis and the definitions of normal and clinical outcomes need to be better studied.

\section{ACKNOWLEDGEMENTS}

Edison Capp is scholarship recipient from the National Council for Scientific and Technological Development (CNPq), Brazil.

\section{CONFLICT OF INTEREST}

The authors have no conflict of interest to declare.

\section{Corresponding author:}

Edison Capp

Serviço de Ginecologia e Obstetrícia Hospital de Clínicas de Porto Alegre Porto Alegre, Rio Grande do Sul, Brazil. E-mail: edcapp@ufrgs.br

\section{REFERENCES}

Ayala C, Steinberger E, Smith DP. The influence of semen analysis parameters on the fertility potential of infertile couples. J Androl. 1996;17:718-25. PMID: 9016403
Catanzariti F, Cantoro U, Lacetera V, Muzzonigro G, Polito M. Comparison between WHO (World Health Organization) 2010 and WHO 1999 parameters for semen analysis - interpretation of 529 consecutive samples. Arch Ital Urol Androl. 2013;85:125-9. PMID: 24085233 DOI: 10.4081/ aiua.2013.3.125

Cooper TG, Noonan E, von Eckardstein S, Auger J, Baker HW, Behre HM, Haugen TB, Kruger T, Wang C, Mbizvo MT, Vogelsong KM. World Health Organization reference values for human semen characteristics. Hum Reprod Update. 2010;16:231-45. PMID: 19934213 DOI: 10.1093/ humupd/dmp048

Deveneau NE, Sinno O, Krause M, Eastwood D, Sandlow JI, Robb P, Granlund A, Strawn EY Jr. Impact of sperm morphology on the likelihood of pregnancy after intrauterine insemination. Fertil Steril. 2014;102:1584-90.e2. PMID: 25439801 DOI: $10.1016 /$ j.fertnstert.2014.09.016

Du Plessis SS, Cabler S, McAlister DA, Sabanegh E, Agarwal $A$. The effect of obesity on sperm disorders and male infertility. Nat Rev Urol. 2010;7:153-61. PMID: 20157305 DOI: $10.1038 /$ nrurol.2010.6 
Erdem M, Erdem A, Mutlu MF, Ozisik S, Yildiz S, Guler I, Karakaya C. The impact of sperm morphology on the outcome of intrauterine insemination cycles with gonadotropins in unexplained and male subfertility. Eur J Obstet Gynecol Reprod Biol. 2016;197:120-4. PMID: 26745391 DOI: $10.1016 /$ j.ejogrb.2015.12.014

Esteves SC, Zini A, Aziz N, Alvarez JG, Sabanegh ES Jr, Agarwal A. Critical appraisal of World Health Organization's new reference values for human semen characteristics and effect on diagnosis and treatment of subfertile men. Urology. 2012;79:1622. PMID: 22070891 DOI: 10.1016/j.urology.2011.08.003

Hamilton JA, Cissen M, Brandes $M$, Smeenk JM, de Bruin JP, Kremer JA, Nelen WL, Hamilton CJ. Total motile sperm count: a better indicator for the severity of male factor infertility than the WHO sperm classification system. Hum Reprod. 2015;30:1110-21. PMID: 25788568 DOI: 10.1093/humrep/dev058

Jurewicz J, Radwan M, Sobala W, Radwan P, Jakubowski L, Hawuła W, Ulańska A, Hanke W. Lifestyle factors and sperm aneuploidy. Reprod Biol. 2014;14:190-9. PMID: 25152516 DOI: $10.1016 /$ j.repbio.2014.02.002

Kaya C, Aykaç A, Kaya Y, Taş M. The effect of modifiable lifestyle factors on semen quality. Rev Int Androl. 2020;18:151-8. PMID: 31953028 DOI: 10.1016/j.androl.2019.09.001

Lingappa HA, Govindashetty AM, Puttaveerachary AK, Manchaiah S, Krishnamurthy A, Bashir S, Doddaiah N. Evaluation of Effect of Cigarette Smoking on Vital Seminal Parameters which Influence Fertility. J Clin Diagn Res. 2015;9:EC13-5. PMID: 26393133 DOI: 10.7860/ JCDR/2015/13295.6227

Talwar P, Hayatnagarkar S. Sperm function test. J Hum Reprod Sci. 2015;8:61-9. PMID: 26157295 DOI: 10.4103/0974-1208.158588
Tharakan T, Bettocchi C, Carvalho J, Corona G, Jones TH, Kadioglu A, Salamanca JIM, Serefoglu EC, Verze P, Salonia A, Minhas S; EAU Working Panel on Male Sexual Reproductive Health. European Association of Urology Guidelines Panel on Male Sexual and Reproductive Health: A Clinical Consultation Guide on the Indications for Performing Sperm DNA Fragmentation Testing in Men with Infertility and Testicular Sperm Extraction in Nonazoospermic Men. Eur Urol Focus. 2021:S2405-4569(20)30319-9. Epub ahead of print. PMID: 33422457 DOI: 10.1016/j.euf.2020.12.017

Vieira M. New World Health Organization reference values for semen analysis: where do we stand? Einstein (Sao Paulo). 2013;11:263-4. PMID: 23843074 DOI: 10.1590/ S1679-45082013000200023

Wang Q, Yu Y, Liu Y, Wang L. Outcome of varicocelectomy on different degrees of total motile sperm count: A systematic review and meta-analysis. Syst Biol Reprod Med. 2019;65:430-6. PMID: 31434522 DOI: $10.1080 / 19396368.2019 .1655813$

WHO. World Health Organization. WHO Laboratory manual for the examination and processing of human semen and sperm-cervical mucus interaction. 4th ed. Cambridge: Cambridge University Press; 1999.

WHO. World Health Organization. WHO Laboratory manual for the examination and processing of human semen. 5th ed. Geneva: WHO Press; 2010.

Zhang E, Tao X, Xing W, Cai L, Zhang B. Effect of sperm count on success of intrauterine insemination in couples diagnosed with male factor infertility. Mater Sociomed. 2014;26:321-3. PMID: 25568631 DOI: 10.5455/ msm.2014.26.321-323 